\title{
Structural Performances of Steel Reinforced Concrete Special Shaped Column-Beam Joints Under Bidirectional Low-Cyclic Reversed Loading
}

\author{
Ping Xiang ${ }^{1}$, H. P. Wang, ${ }^{2}$ * \\ ${ }^{1}$ Department of Architecture and Civil Engineering, City University of Hong Kong, Kowloon, Hong Kong SAR \\ ${ }^{2}$ Department of Civil and Environmental Engineering, Hong Kong Polytechnic University, Hung Hom, Kowloon, Hong Kong SAR
}

\author{
Email address: \\ wanghuaping1128@sina.cn (H. P. Wang), pxiang2-c@my.cityu.edu.hk (Ping Xiang) \\ ${ }^{*}$ Corresponding author
}

\section{To cite this article:}

Ping Xiang, H. P. Wang. Structural Performances of Steel Reinforced Concrete Special Shaped Column-Beam Joints Under Bidirectional Low-Cyclic Reversed Loading. American Journal of Civil Engineering. Vol. 5, No. 1, 2017, pp. 16-20. doi: 10.11648/j.ajce.20170501.13

Received: November 17, 2016; Accepted: November 28, 2016; Published: December 28, 2016

\begin{abstract}
Steel reinforced concrete special-shaped column is a new structural form. It has all priorities of steel reinforced structure and special-shaped column structure. Bearing capacity and ductility of this new structure are very good. It also has very excellent applicable quality and pleasing to the eye. But there are still few experimental and research results relevant to this new structure. The design of steel reinforced concrete special-shaped column joints is a most important problem that must be solved to ensure that this new structural could be widely used in the future. This research focuses the attention on the seismic behavior of this kind of joints, and adopts the new joint design style. The pseudo-static test is carried out on joint specimens. Hysteresis loop of all the specimens have been drawn. The energy dissipating capacities are evaluated. Based on the results of experimental research, the behavior of high resistant capacity, excellent ductility and reliability of the joint design method have been manifested. Taking into account all these facts, this article also put forward practical design suggestions on this structure.
\end{abstract}

Keywords: Steel Reinforced Concrete (SRC) T-shaped Column, Joint, Seismic Behavior, Low-Cyclic Reversed Loading

\section{Introduction}

Steel reinforced concrete (SRC) special-shaped column is a structural style proposed to allow a flexible section pattern and simultaneously satisfy architecture requirements. The structural bearing capacity and ductility are good; thus, SRC special-shaped column-beam frame structures are applicable to building structure design and pleasing to the eye. Special-shaped columns often have the same branch cross sections width with partition wall and will not exceed the wall face. It is regarded as a practical and advisable structure style in fulfilling the requirement of architecture design, which is especially useful in the design of high-rise resident buildings. As the joint is of great importance to a structure frame, Park and Thompson [1] and Park [2] conducted cyclic load test on prestressed and partially prestressed beam-column joints and presented result summaries of simulated seismic load tests on RC beam-column joints. Xiang, Deng [3] studied durability of CFRP-concrete joints under freeze-thaw cycling. Bond-slip behaviors of joints were also intensively investigated [4-10]. Xu, Chen [11] presented a study on seismic-induced damage assessment of three-dimensional joints connected with T-shaped steel SRC column-steel beams. Liu, Xue [12] investigated the cyclic behavior of beam-column abnormal joints in steel moment-resisting frames. Simulation works were taken for the investigation of tubular structures [13-16]. A fracture energy based constitutive model was developed for the analysis of reinforced concrete structures under cyclic loading [15]. In order to investigate steel and concrete filled tubular structures, a series of works on instability, fatigue strength, hysteretic behaviors were conducted by employing cyclic and biaxial loading tests [17-25]. In their works, it was found that the axial compressive force had effects on the strength and ductility. Normal SRC joints are often made by adding welding plate and using hidden bracket on the profiled steel or drilling holes in the web of profile steel in column to connect with bars in RC beam. However, those 
methods are usually difficult to be carried out on site; sometime, the section width of the SRC special column is also not enough for the wielding of plates or steel brackets. So, the application of SRC special-shaped column-beam frame structure is badly in need of a reliable joint design style with the adaptability of onsite construction and excellent mechanical performance. Aimed at satisfying forgoing requirements, this research proposes a design pattern for SRC special-shaped column to RC beam joint with both the consideration of reliable mechanical performance and onsite construction convenience. Seismic behaviors of the proposed joints are evaluated through experimental tests. The mechanical behavior and effectiveness of joint design are also demonstrated.

\section{Test Specimens}

Four specimens named JD-1, JD-2, JD-3 and JD-4 were designed for low-cyclic reversed loading tests. The reinforcement pattern, where steel tube and I-section steel were placed in the column, was adopted in the specimen design. Because the joint is the junction of one column and several beams in a real structure frame, specimens were designed with two RC beams respectively named Beam I and Beam II in orthogonal directions. The two beams met at the beam ends and crossed with the branches of T-shaped SRC column. Joint specimens were designed to fully reflect seismic reactions on the special-shaped joints under bidirectional low-cyclic reversed loading tests. In order to get real performance of the joint under seismic loads, full-scale experiments were conducted to allow a direct, practical assessment of seismic effects on real structure joints. The four specimens, including three SRC T-shaped column joints and one RC T-shaped joint, were designed with the same shape and dimensions but different with each other in the reinforcement. For each specimen, the two beams connected with the T-shaped column were respectively named Beam I and Beam II. All beams in these four specimens had the same section of $250 \mathrm{~mm} \times 450 \mathrm{~mm}$, which was exactly the same as the branch width of T-shaped column. Concrete cube samples were tested at least 28 days after casting.. The specimen design conforms to Chinese code for design of concrete structures [26]. The material sample tests and low-cyclic reversed loading experiments were carried out on the same day to ensure that the material property were reliable to reflect real structure experiments.

\section{Instrumentation and Loading Criteria}

The vertical spaces of the sections with embedded strain gauges were $100 \mathrm{~mm}, 150 \mathrm{~mm}, 200 \mathrm{~mm}$ and $150 \mathrm{~mm}$, respectively, in JD-1 JD-4. Detailed distributions of the strain gauges on steel tube, I-steel and stirrups in every section were designed. Test specimens were subjected to a fixed axial force on top of the column. Test devices of the low-cyclic reversed loading were comparable to the devices of pseudo-static tests established for prestressed concrete beam-composite concrete column joints [27]. Furthermore, this work employed the bidirectional low-cyclic reversed loading on the two orthogonal beam ends. The bidirectional loading allowed the test more realistic than one side beam-column joint test. The test installation was composed of four major elements: back strength wall, reaction frame and two rigid steel hoops placed respectively on the top and bottom of the column. Two welding steel plates were fixed on the top and bottom of the T-shaped column. Meanwhile, two jacks acted on the steel plates to provide axial column loading. The column capital was put in the rigid steel hoop that was fixed on the back strength wall to provide lateral restriction of the entire specimen. Then, the low-cyclic reversed loading was applied on the two beam ends by pulling and pushing the beam ends in turns with two hydraulic jacks.

Tests were conducted under two control stages: force control and displacement control. In the first stage, the force control was applied before yielding of beam reinforcement. In the first two loading cycles of force control stage, the Beam I was pushed down and the Beam II was pulled up simultaneously at the beginning. When the beam end force reached 75 percent of the calculated yielding force, the hydraulic jacks stopped loading. Meanwhile, all the response, including applied force, displacement, angle of rotation, stress and strain in gauges, were recorded. An automatic data acquisition system and manual recording were used to record test results. In the third cycle of force control stage, the two beams were loaded until yielding. After that, the displacement control began. After yielding, the displacement control was adopted until the end of the test. The displacement value applied in each loading step was an increasing integral multiple of the yielding displacement $\Delta$ measured in the stage 1. After recording the date at each displacement increment, the specimen was visually checked. The occurrence of crack was recorded and marked. Before collecting the experiment data, every loading step was maintained for a few minutes until a stable mechanical state was reached. After the collection of all necessary information from a displacement step, a new displacement value was applied on the beam end until the end of the test $[28,29]$.

\section{Analysis of the Test Results}

The hysteresis response of the four specimens is given in Fig. 1. The hysteresis curve could fully reflect the bearing capacity, stiffness, ductility and energy dissipation of the joint, and also an important basis for seismic performance assessment. On account of the limitation of article space, some selected moment-rotation $M-\phi$ and load-shearing deformation $P-\gamma$ curves are presented. It can be seen that the hysteresis curved of SRC special-shaped column joints are flat and generally spindle shaped. It is noteworthy that the energy dissipation behaviors and cyclic loading performances of SRC special-shaped column joints are good. 


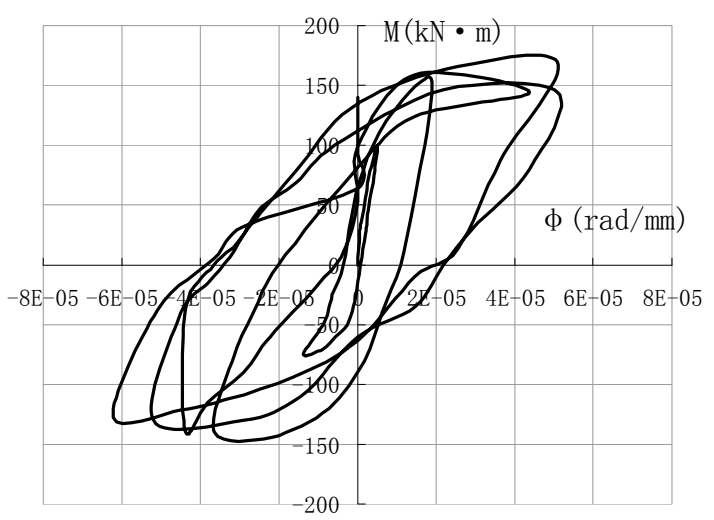

(a)

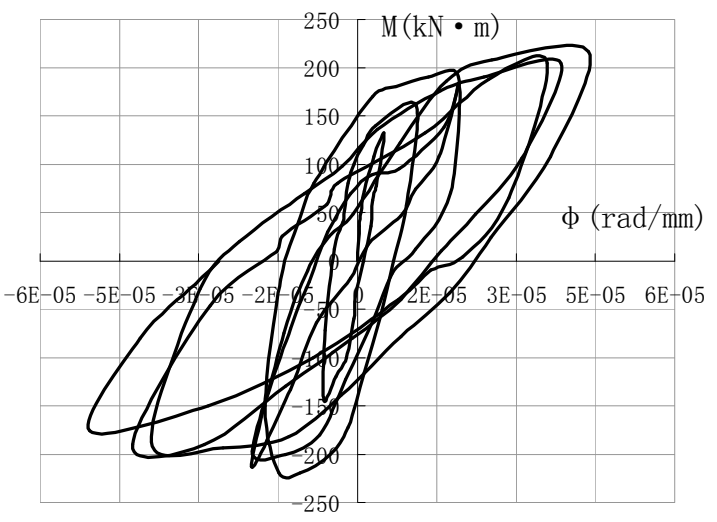

(b)

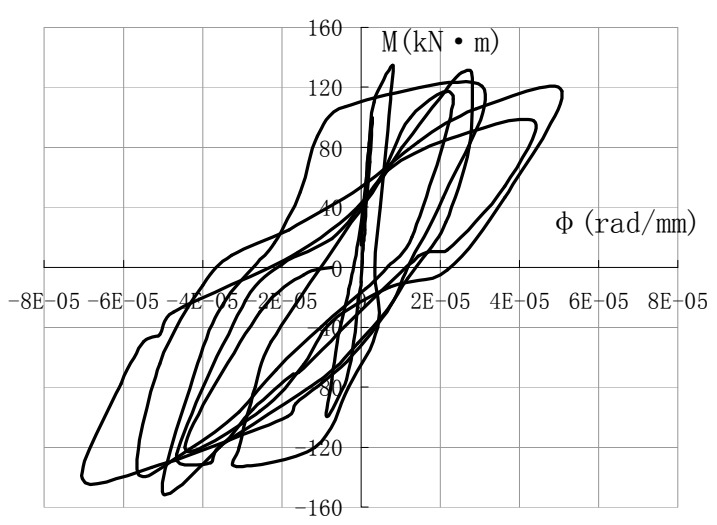

(c)

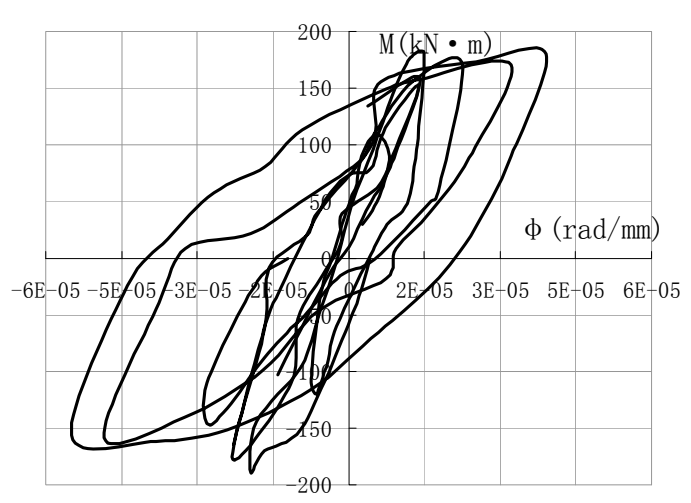

(d)

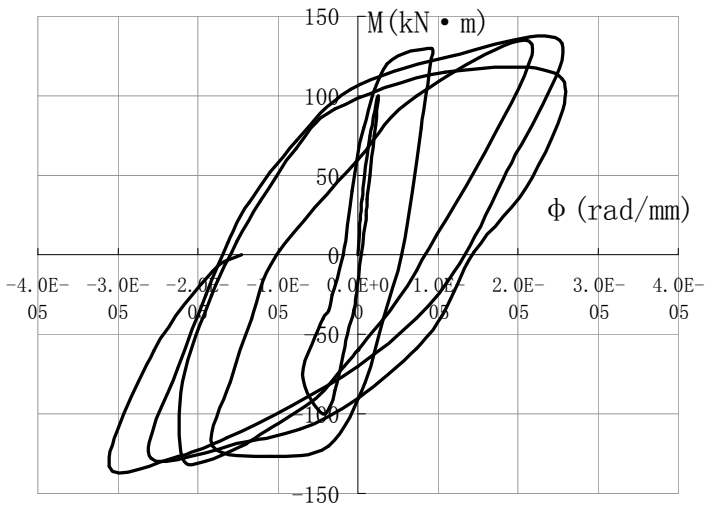

(e)

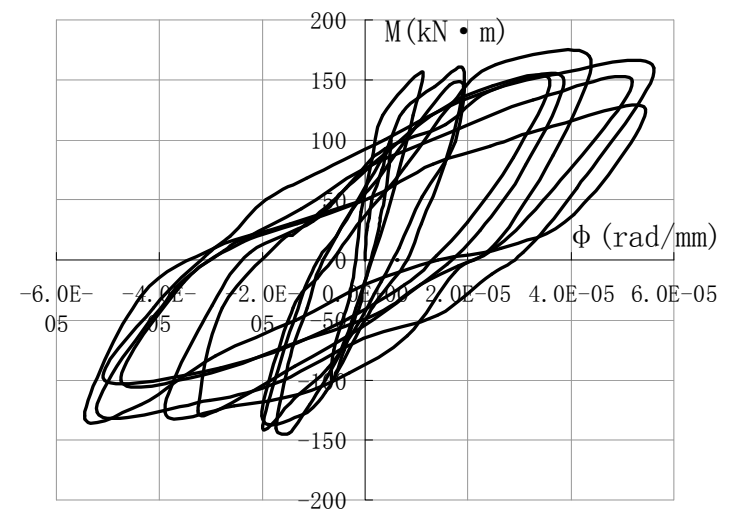

(f)

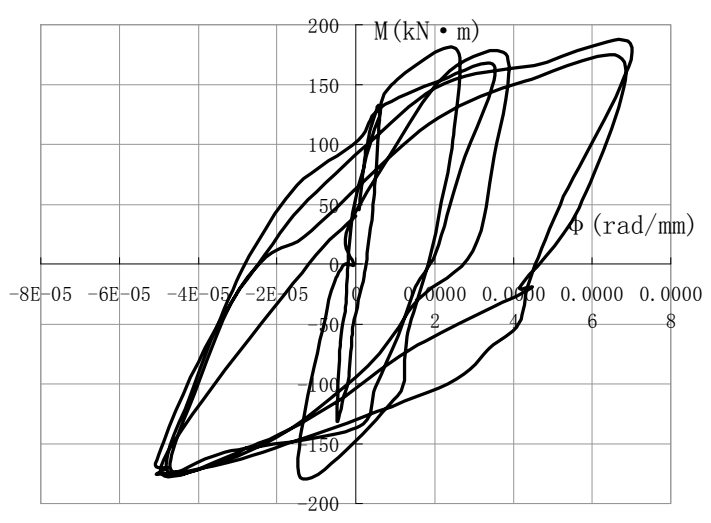

(g)

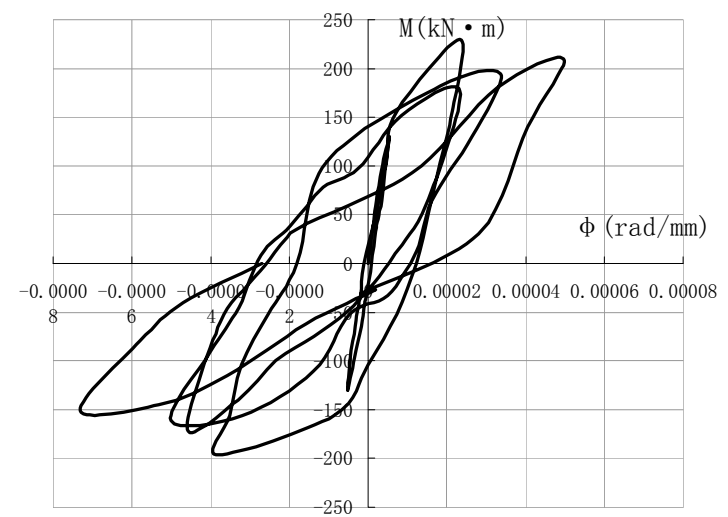

(h) 


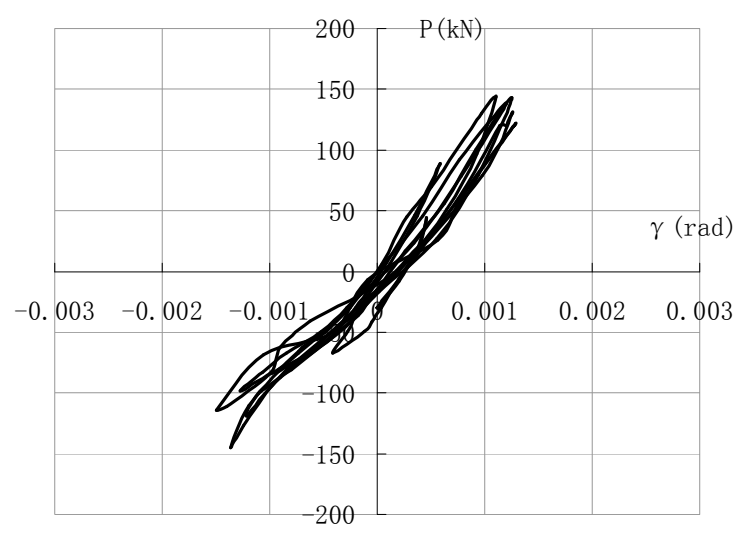

(i)

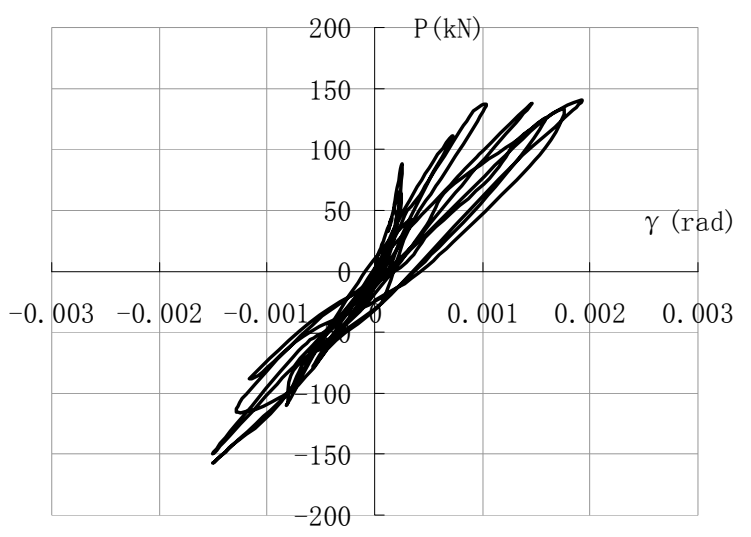

(j)

Figure 1. Hysteresis curved of joint specimens.

\section{Conclusion}

In this work, a SRC-special shaped column joint design was suggested, and a new reinforcement style of joints between SRC-special shaped column and reinforced concrete beam was proposed and tested in this work. The purpose of the insert concrete filled steel tube and I-section steel is to increase the compressive strength and shearing capacity of the joint, as well as the seismic performance under earthquake. It is concluded in this work that the reinforcement style of SRC-special shaped column together with the design method of its joints is reliable and feasible to be applied in engineering practice; seismic behavior has been evaluated as good in the test. Analysis shows that the ductility, capacity degradation, energy dissipation and other evaluation indexes of the joints between SRC-special shaped column and RC beam are good; no significant shearing failure occurred in the joint core area due to the high shearing resistance provided by steel reinforcements; such factors as axial load ratio, steel ratio, stirrup spacing in joint core area may directly affect seismic performance of these joints. In a word, joints between SRC T-shaped column and RC beam investigated in this work have shown a high bearing capacity, shearing strength, excellent seismic performance, which furnish a possible coordination structural design between architecture concepts and structure safety and will surely has good prospects in engineering practice.

\section{Acknowledgements}

The work described in this paper was supported by grants from the National Natural Science Foundation of China (Grant No. 51268005), Guangxi Natural Science Foundation (Grant No. 2013GXNSFAA019311) and General Research Fund of the Hong Kong Special Administrative Region, China (Project No. 9041674, CityU 118411).

\section{References}

[1] Park R, Thompson KJ. Cyclic Load Tests on Prestressed and Partially Prestressed Beam-Column Joints. Journal Prestressed Concrete Institute. 1977; 22: 84-110.

[2] Park R. A summary of results of simulated seismic load tests on reinforced concrete beam-column joints, beams and columns with substandard reinforcing details. Journal of Earthquake Engineering. 2002; 6: 147-74.

[3] Xiang P, Deng ZH, Su YS, Wang HP, Wan YF. Experimental investigation on joints between steel reinforced concrete T-shaped column and reinforced concrete beam under bidirectional low-cyclic reversed loading. Advances in Structural Engineering. 2016; DOI: 10.1177/1369433216653841:

[4] Wu YF, Jiang C. Quantification of Bond-Slip Relationship for Externally Bonded FRP-to-Concrete Joints. Journal of Composites for Construction. 2013; 17: 673-86.

[5] Liu K, Wu YF. Analytical identification of bond-slip relationship of EB-FRP joints. Composites Part B-engineering. 2012; 43: 1955-63.

[6] Yun YC, Wu YF. Durability of CFRP-concrete joints under freeze-thaw cycling. Cold Regions Science And Technology. 2011; 65: 401-12.

[7] Zhou YW, Wu YF, Yun Y. Analytical modeling of the bond-slip relationship at FRP-concrete interfaces for adhesively-bonded joints. Composites Part B-engineering. 2010; 41: 423-33.

[8] Wu YF, Wei YY. Effect of cross-sectional aspect ratio on the strength of CFRP-confined rectangular concrete columns. Engineering Structures. 2010; 32: 32-45.

[9] Wang LM, Wu YF. Effect of corner radius on the performance of CFRP-confined square concrete columns: Test. Engineering Structures. 2008; 30: 493-505.

[10] Chen ZP, Xu JJ, Liang Y, Su YS. Bond behaviors of shape steel embedded in recycled aggregate concrete and recycled aggregate concrete filled in steel tubes. Steel and Composite Structures. 2014; 17: 929-49.

[11] Xu JJ, Chen ZP, Chen YL, Xue JY. Earthquake Damage Evaluation of T-Shaped SRC Composite Column-Steel Beams in 3D Connection Joints. Advances in Structural Engineering. 2015; 18: 701-13.

[12] Liu ZQ, Xue JY, Peng XN, Gao L. Cyclic test for beam-to-column abnormal joints in steel moment-resisting frames. Steel and Composite Structures. 2015; 18: 1177-95. 
[13] Xiang P, Liew KM. A computational framework for transverse compression of microtubules based on a higher-order Cauchy-Born rule. Computer Methods in Applied Mechanics and Engineering. 2013; 254: 14-30.

[14] Xiang P, Liew KM. Predicting buckling behavior of microtubules based on an atomistic-continuum model. International Journal Of Solids And Structures. 2011; 48: $1730-7$.

[15] He W, Wu YF, Liew KM. A fracture energy based constitutive model for the analysis of reinforced concrete structures under cyclic loading. Computer Methods in Applied Mechanics and Engineering. 2008; 197: 4745-62.

[16] Xiang P, Zhang LW, Liew KM. Analysis of macromolecular microtubules using the potential-based matrix displacement method. Composite Structures. 2015; 127: 224-30.

[17] Sugiura K, Lee GC, Watanabe E, Chang KC. Instability of Steel Short Column under Cyclic Loadings. Stability and Ductility of Steel Structures under Cyclic Loading. 1992: 15-23.

[18] Sugiura K, Chang KC, Lee GC. Evaluation of Low-Cycle Fatigue-Strength of Structural Metals. Journal Of Engineering Mechanics-asce. 1991; 117: 2373-83.

[19] Sugiura K, Lee GC, Chang KC. Endochronic Theory for Structural-Steel under Nonproportional Loading. Journal Of Engineering Mechanics-asce. 1987; 113: 1901-17.

[20] Watanabe E, Sugiura K, Kanou M, Takao M, Emi S. Hysteretic Behavior of Thin Tubular Beam-Columns with Round Corners. Journal Of Constructional Steel Research. 1991; 18: 55-69.
[21] Oyawa WO, Sugiura K, Watanabe E. Polymer concrete-filled steel tubes under axial compression. Construction And Building Materials. 2001; 15: 187-97.

[22] Oyawa WO, Sugiura K, Watanabe E. Flexural response of polymer concrete filled steel beams. Construction And Building Materials. 2004; 18: 367-76.

[23] Oyawa WO, Sugiura K, Watanabe E. Polymer concrete filled circular steel beams subjected to pure bending. Steel \& Composite Structures. 2004; 4: 265-80.

[24] Xu C, Sugiura K. Analytical investigation on failure development of group studs shear connector in push-out specimen under biaxial load action. Engineering Failure Analysis. 2014; 37: 75-85.

[25] Watanabe E, Sugiura K, Oyawa WO. Elasto-plastic instability of steel compression tubular members subjected to cyclically applied bi-directional horizontal loads. Thin-Walled Structures. 1998: 809-16.

[26] Code for design of concrete structures. China Architecture and Building Press. GB 50010-2010; Beijing, China.

[27] Xiang P, Liew KM, Sun YZ. Computational of elastic properties of microtubules in eukaryotic cells. Proceedings of City U and USTC Joint Research Forum. 2010: 112.

[28] Standard methods for testing of concrete structures. China Architecture and Building Press. GB50152-92; Beijing, China.

[29] Specification of testing methods for earthquake resistant building. China Architecture and Building Press. JGJ101-96; Beijing, China. 